\title{
Manajemen Pengendalian Gulma Perkebunan Kelapa Sawit (Elaeis guineensis Jacq.): Analisis Faktor- faktor Penentu Dominansi Gulma di Kebun Dolok Ilir, Sumatera Utara
}

\section{Weed Control Managment of Oil Palm Estate (Elaeis guineensis Jacq.): Analysis of determinants factors of Weed Dominancy at Dolok Ilir, North Sumatera}

\author{
Yosua Pratama Simangunsong, Sofyan Zaman* \\ dan Dwi Guntoro
}

\begin{abstract}
Departemen Agronomi dan Hortikultura, Fakultas Pertanian, Institut Pertanian Bogor (Bogor Agricultural University), Jl. Meranti, Kampus IPB Dramaga, Bogor 16680, Indonesia

Telp.\&Faks.62-251-8629353 e-mail agronipb@indo.net.id

*Penulis untuk korespondensi : sofyan_zaman@yahoo.com
\end{abstract}

Disetujui 14 Mei 2018 / Published online 21 Mei 2018

\begin{abstract}
The research aims to expand the knowledge and skills of the technical and managerial aspects, especially in weed control management activities. Research activities was conducted at estate Dolok Ilir, North Sumatera from February and June 2016. Analysis planting vegetation at 5 years by taking 30 examples in each year of planting (YP). Observation micro-climate factors and the level of fertile do in the garden Cikabayan IPB. Microclimate daily observations carried out 5 different times. Determinants factors of dominance weeds analyzed correlations against SDR dominant weeds. Determinants of test results showed the dominance of weed fertilization activities were negatively correlated to the degree of dominance of A. aciculatus and cover crops negatively correlated to the level of dominance D.ciliaris. In the aspect of edafik, and the microclimate of oil palm trees, weeds dominance level $R$. rundana negatively correlated to temperature and positively correlated to the total nutrient content of phosphorus in the soil. The level of dominance weeds S. plicata positively correlated to the levels of soil CEC, and soil $p H$. The level of dominance weeds $P$. polystachion positively correlated to the levels of potassium in the soil. The level of dominance weeds $O$. nodosa which dominates in any open area positively correlated to the level of light intensity, and negatively correlated to the level of humidity.
\end{abstract}

Keyword: Dominance, grass, weed, managment

\begin{abstract}
ABSTRAK
Kegiatan penelitian ini bertujuan untuk memperluas pengetahuan dan keterampilan tentang aspek teknis dan manajerial terutama dalam kegiatan manajemen pengendalian gulma. Kegiatan penelitian dilaksankan di Kebun Dolok Ilir, Sumatera Utara pada bulan Februari hingga Juni 2016. Analisis vegetasi pada 5 tahun tanam dengan mengambil 30 contoh pada setiap tahun tanam (TT). Pengamatan faktor iklim mikro dan tingkat kesuburuan dilakukan di kebun Cikabayan IPB. Pengamatan iklim mikro harian dilakukan 5 waktu yang berbeda .Faktor- faktor penentu dominansi gulma dianalisis secara korelasi terhadap NJD gulma yang dominan. Hasil uji faktor- faktor penentu dominasi gulma menunjukkan kegiatan pemupukan berkorelasi negatif pada tingkat dominansi A. aciculatus dan tanaman penutup tanah berkorelasi negatif terhadap tingkat dominansi $D$. ciliaris. Aspek edafik, dan iklim mikro tanaman kelapa sawit, tingkat dominansi gulma $R$. rundana berkorelasi negatif terhadap suhu udara, berkorelasi positif pada kandungan total unsur hara fosfor di dalam tanah. Tingkat dominansi gulma $S$. plicata berkorelasi positif terhadap kadar KTK tanah, pH tanah. Tingkat dominansi gulma P.polystachion berkorelasi positif terhadap kadar kalium dalam tanah. Tingkat dominansi gulma $O$. nodosa yang mendominasi pada setiap daerah terbuka berkorelasi positif terhadap tingkat intensitas cahaya, dan berkorelasi negatif terhadap tingkat kelembapan.
\end{abstract}

Kata kunci : Dominansi, rumput, gulma, manajemen 


\section{PENDAHULUAN}

Komoditas kelapa sawit di Indonesia dewasa ini telah menjadi tanaman primadona dan memiliki prospek masa depan yang sangat cerah. Usaha kelapa sawit yang diintroduksi oleh Adrien Heller menjadikan kelapa sawit memiliki arti penting bagi pembangunan perkebunan nasional (Fauzi, 2012). Perkembangan kelapa sawit di Indonesia dapat dilihat dari peningkatan luas areal budidaya. Berdasarkan data dari Badan Pusat Statistik Indonesia (2014), peningkatan luas areal perkebunan kelapa sawit dari 4713435 ha pada tahun 2001 menjadi 10465020 ha pada tahun 2014. Peningkatan luas areal juga diimbangi dengan peningkatan produksi Minyak Kelapa Sawit (MKS). Produksi MKS pada tahun 2001 sebesar 26015.52 ton/ha dan meningkat menjadi 29344.48 ton/ha pada tahun 2014.

Pengelolaan suatu perkebunan kelapa sawit mengacu pada pengeloaan tanaman agar dapat meningkatan produktivitas tandan buah segar kelapa sawit (TBS). Unsur- unsur pengeloalan perkebunan diantaranya pemilihan tanah, bahan tanam, manajemen teknis, panen dan lingkungan. Unsur- unsur tersebut dikelola dan terintegrasi satu sama lain guna memperoleh produksi yang ditargetkan oleh sebuah perusahaan. (Salmiyati et al, 2014).

Faktor- faktor yang mempengaruhi pertumbuhan dan produktivitas kelapa sawit dapat dikelompokkan dalam tiga faktor, yakni: 1) lingkungan; 2) bahan tanaman; 3) tindakan kultur teknis (Setyamidjaja, 2012). Perlindungan tanaman berupa tindakan pengendalian hama dan penyakit merupakan salah satu aspek dari tindakan kultur teknis yang paling banyak mempengaruhi pertumbuhan dan produktivitas. Pengendalian hama berupa pengendalian gulma merupakan usaha untuk meningkatkan daya saing tanaman pokok dan melemahkan daya saing gulma (Pahan, 2008). Menurut Kementrian Pertanian (2013), gulma pada tanaman kelapa sawit dapat menurunkan produktivitas, seperti gulma Mikania micrantha dapat menurunkan produksi TBS sebesar $20 \%$.

Dinamika populasi gulma yang ada pada kelapa sawit dipengaruhi oleh banyak faktor diantaranya adalah lingkungan, kultur teknis, dan tanaman (Tantra dan Santosa, 2016). Faktorfaktor tersebut juga menentukan tingkat keberhasilan atau efektivitas dalam kegiatan pengendalian. Keberhasilan gulma dalam berkompetisi, memodifikasi dan memanfaatkan lingkungan tumbuh akan menimblukan dominasi terhadap tanaman utama.
Menurut Pahan (2008), kegiatan pengendalian gulma yang umum dilakukan di perkebunan diantaranya pengendalian secara manual, pengendalian secara kimia dan pengendalian secara kultur teknis. Pengendalian gulma manual adalah menggunakan alat cangkul dan sebagainya, sedangkan pengendalian secara kimia adalah menggunakan herbisida. Herbisida yang digunakan ada yang bersifat kontak dan ada yang bersifat sistemik. Selain itu, ada herbisida yang memiliki spektrum luas dan spektrum sempit. Pengendalian gulma secara kultur teknis antara lain dengan menanam LCC atau memelihara keberadaan serangga pemakan gulma. Strategi yang digunakan dalam kegiatan pengendalian dapat berbeda-beda antar kebun (spasial) dan antar waktu (temporal). Oleh karena itu, penting untuk dikaji bagaimana pemilihan kegiatan pengendalian gulma tersebut dilakukan.

Faktor- faktor penentu dominasi gulma merupakan faktor yang menentukan gulma mendominasi suatu areal lahan. Pemahaman tentang faktor- faktor yang menentukan gulma tumbuh dan mendominasi suatu areal akan menjadi suatu bahan pertimbangan dalam perencanaan pengendalian gulma di lapang. Kegiatan penelitian yaitu mengamati lingkungan mikro kelapa sawit, tindakan kultur teknis di perkebunan, dan mengambil contoh tanah untuk dinilai tingkat keseburuannya. Tujuan kegiatan penelitian secara khusus yaitu mengidentifikasi gulma yang ada di perkebunan dan menganalisis faktor- faktor penentu dominansi terhadap tingkat dominansi gulma yang dominan.

\section{METODE PENELITIAN}

Kegiatan penelitian dilaksanakan pada bulan Februari 2016 - Juni 2016 bertempat di kebun PTPN IV unit usaha Dolok Ilir afdeling VI. Aspek yang dipelajari meliputi aspek teknik dan manajerial kebun.

\section{Pengamatan dan Pengumpulan Data}

Kegiatan pengumpulan data dilakukan guna mendapatkan data primer dan data sekunder. Data primer yang didapatkan dari lapangan adalah dominansi jenis gulma dan kultur teknis yang diterapkan di perkebunan. Pengamatan dilakukan di beberapa blok tertentu berdasarkan tahun tanam baik itu tanaman yang sudah menghasilkan maupun tanaman belum menghasilkan.

Data sekunder diperoleh dari arsip perusahaan sebagai acuan dan penunjang dalam melakukan perbandingan dan analisis data. Data ini berupa norma kerja yang diterapkan oleh perusahaan berupa jenis dan dosis herbisida yang 
diaplikasikan, sistem organisiasi dan manajen kerja pada kebun tersebut.

Pengukuran tingkat dominansi setiap spesies gulma diketahui dengan melakukan analisis vegetasi metode kuadrat. Kuadran yang digunakan berukuran $0,5 \mathrm{~m}$ x 0,5 m. Pengamatan dilakukan pada kelapa sawit tahun tanam 1990, tahun tanam 1994, tahun tanam 1998, tahun tanam 2010, dan tahun tanam 2013. Hal ini didasarkan pada penutupun kanopi. Pada setiap tahun tanam diambil 30 contoh dengan proporsi lemparan, 15 contoh pada piringan dan 15 contoh pada gawangan. Pengamatan contoh di piringan diambil pada baris ganjil dari pasar 200 ke arah utara, sementara pengamatan contoh di gawangan diambil pada baris genap dari pasar $200 \mathrm{ke}$ arah selatan. Setiap baris diambil 2 contoh. Pada analisis vegetasi yang dilakukan terdapat tiga peubah yang dinilai diantaranya kerapatan mutlak $(\mathrm{KM})$, bobot basah mutlak (BBM), dan frekuensi mutlak (FM). KM adalah jumlah individu spesies gulma tertentu dalam petak contoh, BBM adalah bobot spesies gulma tertentu dalam petak contoh, dan FM adalah jumlah petak contoh yang memuat spesies gulma tertentu.

Pengamatan juga dilakukan di kebun percobaan Cikabayan IPB. Pengamatan yang dilakukan berupa pengamatan iklim mikro, pengambilan contoh tanah, dan analisis vegetasi gulma kelapa sawit pada tanaman kelapa sawit menghasilkan yang berumur lebih dari 15 tahun, tanaman kelapa sawit menghasilkan yang berumur 7 tahun, serta tanaman kelapa sawit belum menghasilkan. Iklim mikro yang diamatin berupa kelembapan, tingkat intensitas cahaya, dan suhu. Pengamatan iklim mikro dilakukan pada pukul 07:00, 10:00: 13:00, 15:00, dan 17:00. Contoh tanah yang diperoleh diuji di lab pengujian IPB untuk dinilai tingkat kesuburannya.

\section{Analisis Data dan Informasi}

1. Tingkat dominasi gulma

Tiga peubah yang diamati, diantaranya: kerapatan mutlak (KM), bobot basah mutlak (BBM), dan frekuensi mutlak (FM). Nilai nisbah jumlah dominasi (NJD) menunjukan dominansi suatu gulma yang ada di suatu lokasi tertentu. Nilai NJD gulma tinggi maka dominansi gulma di areal tersebut tinggi, dan sebaliknya makin rendah nilai NJD, dominansi gulma semakin rendah. persamaan:

NJD dapat dihitung dengan menggunakan

$$
N J D=\frac{K N+B B N+F N}{3}
$$

Keterangan:

$\mathrm{KN}=$ Kerapatan nisbih

$\mathrm{BBN}=$ Berat basah nisbih
FN $\quad=$ Frekuensi nisbih

Kerapatan nisbih (KN) dihitung dengan menggunakan persamaan:

$$
\mathrm{KN}=\frac{\text { KM spesies gulma tertentu }}{\text { KM semua jenis gulma }}
$$

BBN dihitung dengan menggunakan persamaan:

$$
\mathrm{BBN}=\frac{\mathrm{BBM} \text { spesies gulma tertentu }}{\text { BBM semua jenis gulma }}
$$

FN dapat dihitung dengan menggunakan persamaan:

$$
\mathrm{FN}=\frac{\mathrm{FM} \text { spesies gulma tertentu }}{\text { FM semua jenis gulma }}
$$

\section{Koefisien komunitas}

Analisis koefisien komunitas (KK) berguna untuk menunjukkan tingkat kesamaan vegetasi gulma setiap blok pengamatan. Nilai KK sebesar $75 \%$ atau lebih menunjukkan vegetasi di suatu areal relatif homogen. Koefisien komintas diperoleh dari nilai nisbah jumlah dominansi (NJD).

Koefisien Komunitas (KK) dapat dihitung dengan menggunakan persamaan:

Keterangan:

$$
K K=\frac{2 W}{a+b} \times 100 \%
$$

$\mathrm{W}=$ jumlah spesies gulma terendah pada 2 blok yang dibandingkan.

$\mathrm{a}=$ jumlah semua individu spesies gulma pada blok pertama.

$\mathrm{b}=$ jumlah semua individu spesies gulma pada blok kedua.

3. Faktor- faktor penentu dominansi gulma

Faktor- faktor penentu dominansi gulma, diantaranya: 1) faktor iklim mikro; 2) faktor edafik terkait tingkat kesuburan lahan; 3) faktor kultur teknis yang diterapkan di perkebunan. Faktor tersebut kemudian dianalisis untuk melihat apakah ada hubungan atau korelasi dalam menentukan gulma yang mendominasi di suatu areal.

\section{HASIL DAN PEMBAHASAN}

\section{Manajemen Pengendalian Gulma}

Pada afdeling VI terdapat 10 tahun tanam (TT), diantaranya; TT 1900, TT 1992, TT 1993, TT 1994, TT 1998, TT 1999, TT 2010, TT 2011, TT 2012, dan TT 2013. Pemeliharan terhadap kelapa sawit berupa pengendalian gulma dan pemupukan dilakukan pada TT 1999, TT 2010, TT 2011, TT 2012, dan TT 2013. Dua jenis pengendalian gulma yang dilakukan, diantaranya pengendalian secara kimiawi dan pengendalian secara manual. Pengendalian gulma secara manual diterapkan pada gulma yang memiliki 
struktur sekulen ataupun menjalar secara invasif, dan babat merah pada piringan di pasar koleksi. Pengendalian gulma secara kimiawi merupakan cara yang paling utama yang diterapkan di perusahaan ini.

Kegiatan persiapan yang dilakukan sebelum pengendalian adalah perencanaan kegiatan. Kegiatan persiapan yang dilakukan diantaranya: menentukan lokasi pengendalian dengan mengacu pada rotasi pengendalian gulma, menentukan jumlah tenaga kerja yang dibutuhkan, mempersiapkan herbisida yang dibutuhkan. Kegiatan persiapan terutama dilaksanakan oleh mandor besar dan mandor pemeliharaan.

Secara khusus pada pengendalian gulma secara kimiawi, setiap regu dibantu oleh tenaga pembantu yang bertugas untuk mengangkut air dan herbisida, dan sebelum pengaplikasian herbisida di lapang terlebih dahulu dilakukan pengenceran yang bertujuan untuk keamanan dari tindakan pencurian bahan aplikasi.

\section{Gulma Dominan dan Koefisien Komunitas}

Hasil analisis vegetasi gulma pada perkebunan kelapa sawit di Kebun Dolok Ilir terdapat 49 spesies gulma gulma, terdiri dari 41 spesies dari golongan daun lebar, 6 spesies dari golongan rumput, dan 2 spesies dari golongan teki. Komposisi jenis gulma yang tumbuh dominan di kebun dolok ilir berbeda berdasarkan tahun tanamnya. Pada tanaman kelapa sawit tahun tanam 1990 terdapat 20 spesies gulma, pada tahun tanam 1994 terdapat 26 spesies gulma, pada tahun tanam 1998 terdapat 16 spesies, pada tahun tanam
2010 terdapat 23 spesies gulma, dan pada tahun tanam 2013 terdapat 22 spesies gulma.

Jumlah spesies gulma pada kelapa sawit tahun tanam muda dengan kelapa sawit tahun tanam muda tidak menunjukkan perbedaan yang signifikan. Tingkat populasi yang beragam ini dipengaruhi oleh penutupan kanopi kelapa sawit. Tingkat penutupan kanopi oleh tumbuhan mempengaruhi tingkat intensitas cahaya yang diterima oleh tumbuhan yang berada dibawah naungan kanopi. Faisal (2013) menyatakan semakin tinggi intensitas cahaya mencapai tumbuhan menyebabkan daun-daun tumbuhan makin jenuh oleh cahaya sehingga laju fotosintesis menjadi maksimum dan pertumbuhan meningkat. Hal ini dikarenakan kebun Dolok ilir akan melaksanakan penanaman ulang pada kelapa sawit tahun tanam 1999 hingga kelapa sawit tahun tanam 1990. Populasi yang rendah pada tanaman tua menyebabkan areal mendapatkan tingkat intensitas cahaya yang tinggi seperti pada areal kelapa sawit tahun tanam muda.

Data hasil analisis vegetasi dapat dijadikan dasar untuk melakukan pengelolaan gulma di perkebunan kelapa sawit, terkhususnya gulma dominan dapat dijadikan sasaran utama dalam tindakan pengelolaan gulma. Pengelolaan gulma meliputi penentuan jenis pengendalian gulma, penentuan jumlah tenaga kerja, dan penentuan jenis herbisida yang akan digunakan. Gulma dominan yang diperoleh dari kegiatan analisis vegetasi di kebun dolok ilir dapat dilihat pada tabel dibawah ini.

Tabel 1. Gulma dominan di afdeling VI kebun Dolok Ilir

\begin{tabular}{|c|c|c|}
\hline Tahun Tanam & Spesies & NJD (\%) \\
\hline 1990 & Andropogon aciculatus & 21,04 \\
\hline 1994 & Digitaria ciliaris & 30,57 \\
\hline 1998 & Eleusine indica & 28,84 \\
\hline 2010 & Cynodon dactylon & 23,39 \\
\hline 2013 & Digitaria ciliaris & 17,97 \\
\hline
\end{tabular}

Sumber: Hasil analisis vegetasi di kebun Dolok ilir afdeling VI

Areal kelapa sawit tahun tanam 2013 dan tahun tanam 1994 didominasi oleh gulma Digitaria ciliaris. Gulma ini merupakan golongan tumbuhan $\mathrm{C} 4$ yang memiliki daya adaptasi yang baik pada lingkungan yang kering dan panas. Digitaria ciliaris berkembang biak dengan baik secara generatif dengan biji. Perkembangan yang tinggi membuat potensi biji gulma yang jatuh ke tanah juga tinggi. Menurut Cauhan dan Jhonson (2008) tingkat keberhasilan perkecambahan biji gulma Digitaria ciliaris lebih dari $87 \%$ bila terpapar suhu hingga $80^{\circ} \mathrm{C}$ selama 5 menit sebelum imbibisi. Kondisi terbuka di areal kelapa sawit tahun tanam 1990 menjadi lingkungan yang sesuai untuk tumbuhnya gulma Digitaria ciliaris.

Pada areal kelapa sawit tahun tanam 1998 didominasi oleh gulma Eleusine indica. Tingkat dominansi gulma pada areal ini sebesar $28,84 \%$. Gulma yang tergolong invasif ini berkembang biak secara generatif melalui biji. Satu tumbuhan Eleusine indica dapat menghasilkan 50000 lebih biji kecil yang dapat disebarkan oleh angin dan air, serta dapat melekat pada bulu dan mesin dan sebagai kontaminan dalam tanah (Cabi, 2014) Struktur biji dan kemampuan perbanyakan yang tinggi membuat gulma semusim ini, Eleusine 
indica, berpotensi hadir sepanjang tahun dan ditemukan di seluruh areal kelapa sawit.

Cynodon dactylon merupakan gulma dominan di areal tanaman kelapa sawit tahun tanam 2010 dengan nilai NJD sebesar 23,39\%. Gulma yang tergolong tanaman $\mathrm{c} 4$ ini merupakan salah satu gulma invasif di banyak negara negara, termasuk Indonesia (Cabi, 2014). Perbanyakan gulma Cynodon dactylon dilakukan dengan cara stolon dan biji. Pertumbuhan gulma yang cepat berkolonisasi ini memiliki potensi untuk mengubah fungsi ekosistem dengan mengubah siklus hidrologi, dinamika biofisik, siklus nutrisi, dan komposisi komunitas (D'Antonio dan Vitousek, 1992). Berdasarkan hasil analisis vegetasi dan potensi yang dimiliki, gulma Cynodon dactylon hampir ditemukan di seluruh areal.

Tingkat homogenitas komunitas antar areal yang berbeda dapat dinilai dengan menghitung nilai koefisien komunitasnya. Hasil analisis terhadap analisis vegetasi yang dilakukan oleh peneliti dapat dilihat pada tabel dibawah ini.

Tabel 2. Analisis koefisien komunitas (KK)

\begin{tabular}{ccccc}
\hline Tahun Tanam $($ TT $)$ & KK TT1990 $(\%)$ & KK TT1994 (\%) & KK TT1998 $(\%)$ & KK TT2010 $(\%)$ \\
\hline KK TT1994 & 86,72 & - & - & - \\
KK TT1998 & 51,99 & 48,88 & - & - \\
KK TT2010 & 68,97 & 61,12 & 66,68 & - \\
KK TT2013 & 57,78 & 63,41 & 51,16 & 41,93 \\
\hline
\end{tabular}

Sumber: Hasil analisis koefisien komunitas di lapang

Hasil analisis koefisien komunitas menunjukkan hanya pada kelapa sawit tahun tanam 1990 dan kelapa sawit1994 yang menunjukkan kehomogenan komunitas dengan nilai koefisien komunitas KK sebesar 86,72\%. Kegiatan pemeliharaan yang tidak dilakukan, lokasi penanaman yang berdekatan, serta populasi tanaman yang rendah membuat vegetasi pada kedua areal ini homogen. Penutupan kanopi yang berbeda menyebabkan perbedaan komunitas gulma pada areal kelapa sawit belum menghasilkan, tahun tanam 2013, dengan kelapa sawit areal kelapa sawit menghasilkan, tahun tanam 1990-2010.

\section{Faktor-faktor Penentu Dominansi Gulma}

Analisis korelasi dilakukan untuk mengetahui adanya korelasi atau pengaruh faktorfaktor pertumbuhan terhadap tingkat dominansi gulma pada sautu areal tanam. Faktor- faktor dalam pengujian yaitu, faktor iklim mikro, faktor edafik yang merujuk pada tingkat kesuburan tanah, dan kegiatan kultur teknis yang dilakukan pada areal perkebunan. Kondisi iklim mikro secara langsung mempengaruhi proses fisiologi karena berhubungan dengan atmosfer di lingkungan tanaman sejak perakaran hingga puncak tajuk. Menurut Noorhadi dan Sudadi (2003), Komponen iklim mikro yang mempengaruhi pertumbuhan adalah kelembaban udara dan tanah, suhu udara dan tanah.

Tabel 3. Hasil analisis korelasi terhadap gulma dominan tanaman kelapa sawit tahun tanam 1990, tahun tanam 2010 dan tahun tanam 2013 di Kebun Dolok Ilir afdeling VI

\begin{tabular}{llccc}
\hline & & TT 1990 & TT 2010 & TT 2013 \\
& Parameter & NJD Andropogon & NJD Cynodon dactylon & NJD Digitaria \\
aciculatus $(\mathrm{R})$ & $(\mathrm{R})$ & 0,029 & 0,454 \\
Kultur & Kegiatan pemupukan & $-0,992^{*}$ & $-0,128$ & $-0,909^{*}$ \\
\hline
\end{tabular}

Keterangan: Angka yang diikuti simbol $(*)$ menunjukkan adanya korelasi yang nyata pada taraf $\alpha=5 \%$

Kegiatan pemupukan merupakan kegiatan yang utama dalam budidaya kelapa sawit guna meningkatkan produktivitas tandan buah segar (TBS). Perusahaan PTP Nusantara IV unit usaha kebun Dolok ilir menggunakan pupuk organik dan anorganik. Pupuk organik yang digunakan berupa pemberian janjangan kosong hasil pengolahan TBS. Kegiatan pemupukan juga dapat berpengaruh pada pertumbuhan dan perkembangan gulma. Berdasarkan hasil analisis korelasi, kegiatan pemupukan berkorelasi negatif terhadap pertumbuhan gulma. Hal ini menunjukkan pertumbuhan gulma, Andropogon aciculatus, terhambat ketika dilakukan pemupukan. Kejadian ini juga pernah diteliti pada pemberian pupuk kandang ayam pada pertanaman jagung manis yang dapat menurunkan berat kering gulma, sementara pemberian pupuk kandang sapi dan kambing tidak dapat menurunkan pertumbuhan gulma (Mayadewi, 2007). Berdasarkan hasil penelitian Nasution (2013), Kombinasi pemberian pupuk anorganik 
pada tanaman dan pengendalian gulma secara kimiawi dengan bahan aktif ametrin dapat menekan bobot kering gulma.

Kebun Dolok Ilir menggunakan Mucuna bracteta sebagai tanaman penutup tanah. Tanaman penutup tanah secara intensif dipelihara pada tanaman kelapa sawit yang belum menghasilkan dan tanaman kelapa sawit menghasilkan yang masih muda, seperti tanaman kelapa sawit tahun tanam 2011-2012. Tanaman penutup tanah memiliki banyak fungsi, diantaranya; pencegahan pencucian nitrogen, perbaikan struktur tanah, meningkatkan fiksasi nitrogen di tanah, dan dapat mengendalian penyakit menular dari tanah, seperti nematoda (Kruidhof et al., 2008). Digitaria ciliaris merupakan tumbuhan golongan $\mathrm{C} 4$ yang optimal tumbuh pada lingkungan kering dan memiliki intensitas cahaya tinggi. Berdasarkan hasil korelasi, penekanan pertumbuhan gulma
Digitaria ciliaris dapat dilakukan dengan membuat tanaman penutup tanah. Tingkat intensitas cahaya yang berkurang memberikan dampak pada penekanan populasi gulma Digitaria ciliaris.

Hasil analisis vegetasi di kebun Cikabayan IPB menunjukkan gulma dominan pada tanaman belum menghasilkan di daerah piringan adalah Penisetum polystachyon pada derah piringan dengan NJD 18,96\%, gulma Setaria plicata mendominasi di daerah piringan pada tahun tanam muda dengan NJD 22,39, gulma Rostellularia rundana mendominasi di daerah piringan pada tanaman tua dengan NJD 48,48, dan gulma Ottochloa nodosa mendominasi di daerah gawangan pada setiap tahun tanam.

Hasil uji korelasi tingkat dominansi gulma dominan terhadap faktor iklim mikro dan faktor edafik dapat dilihat pada tabel di bawah ini.

Tabel 4. Hasil analisis korelasi terhadap gulma dominan pada kelapa sawit menghasilkan berumur muda, kelapa sawit menghasilkan berumur tua, dan kelapa sawit belum menghasilkan di kebun IPB Cikabayan.

\begin{tabular}{llcccc}
\hline & \multirow{2}{*}{ Parameter } & NJD & NJD & NJD & NJD \\
& R. rundana $(\mathrm{R})$ & O. nodosoa $(\mathrm{R})$ & $\begin{array}{c}\text { P. polystachyon }(\mathrm{R}) \\
\text { Iklim Mikro plicata }(\mathrm{R})\end{array}$ \\
\hline \multirow{4}{*}{ Suhu udara } & $-0,839^{*}$ & 0,783 & 0,356 & 0,050 \\
& Kelembapan udara & 0,581 & $-0,902^{*}$ & $-0,043$ & 0,202 \\
& Intensitas Cahaya & $-0,338$ & $0,961^{*}$ & 0,409 & $-0,391$ \\
\hline & KTK & $-0,130$ & $-0,517$ & $-0,540$ & $0,889^{*}$ \\
& $\mathrm{~K}$ & 0,798 & $-0,236$ & $0,347^{*}$ & $-0,277$ \\
& $\mathrm{Ph}(\mathrm{H} 20)$ & $-0,274$ & $-0,222$ & $-0,268$ & $0,910^{*}$ \\
& Ph (KCl) & $-0,282$ & $-0,28$ & $-0,096$ & $0,897^{*}$ \\
& N tot & 0,698 & $-0,37$ & $-0,541$ & $-0,170$ \\
& C-Org & 0,669 & $-0,328$ & $-0,516$ & $-0,213$ \\
& P tot & $0,972^{*}$ & $-0,320$ & $-0,419$ & $-0,369$ \\
& K tot & 0,620 & $-0,443$ & $-0,556$ & $-0,441$ \\
& P2O5 & $-0,068$ & 0,041 & $-0,363$ & $-0,110$ \\
\hline
\end{tabular}

Keterangan: Angka yang diikuti simbol (*) menunjukkan adanya korelasi yang nyata pada taraf $\alpha=5 \%$

Suhu berpengaruh terhadap fisiologi tumbuhan,pengaruh yang diberikan antara lain; pembukaan stomata, laju transpirasi, laju penyerapan air dan nutrisi, fotosintesis, dan respirasi. Suhu yang terlalu tinggi atau terlalu rendah akan menghambat proses pertumbuhan. Hasil analisis korelasi menunjukkan pertumbuhan gulma Rostelluaria rundana terhambat pada suhu yang tinggi. Hal ini terbukti pada dominansi gulma ini pada areal yang memiliki tingkat naungan yang tinggi. Penutupan kanopi kelapa sawit mempengaruhi suhu udara di bawah naungan. Respon pertumbuhan gulma Rostelluaria rundana juga dipengaruhi oleh kandungan fosfor dalam tanah. Fosfor sangat berguna bagi tumbuhan untuk merangsang pertumbuhan akar pada awal pertumbuhan, mempercepat pembungaan, dan pemasakan biji dan buah (Rosmarkam et al., 2002). Perbanyakan Rostelluaria rundana dilakukan secara generatif, sehingga kandungan forfor dalam tanah yang semakin tinggi akan memacu pertumbuhan gulma ini.

Gulma Ottochloa nodosoa merupakan tanaman $\mathrm{C} 4$. Tumbuhan $\mathrm{C} 4$ yang memiliki daya adaptasi yang baik pada lingkungan yang kering dan panas. Hasil korelasi menunjukkan tingkat intensitas cahaya yang semakin tinggi memacu pada pertumbuhan dan perkembangan gulma ini, sementara tingkat kelembapan yang semakin tinggi akan menghambat pertumbuhan dan perkembangan gulma ini. Semakin tingi tingkat intensitas cahaya akan meningkatkan suhu udara 
di sekitar pertanaman, dan tingkal kelembapan menjadi rendah.

Gulma Pennisettum polstachion merupakan gulma golongan rumput tahunan. Gulma ini digolongkan gulma invasif karena pertumbuhannya. Pennisettum polstachion dapat tumbuh hingga 3 meter, dan biji yang dihasilkan sangat banyak dengan karakteristik dormansi biji yang terbatas (Cabi, 2008). Hasil korelasi menunjukkan gulma ini berkorelasi terhadap kadar kalium dalam tanah. Kalium memiliki fungsi bagi tanaman dalam pembentukan pati, mengaktifkan enzim, pembukaan stomata, proses fisiologis dalam tanaman, proses metabolik dalam sel, mempengaruhi penyerapan unsur-unsur lain, mempertinggi daya tahan terhadap kekeringan, penyakit dan berperan dalam perkembangan akar (Kementan, 2014).

Gulma Setaria plicata merupakan gulma tahunan golongan rumput yang biasa hidup pada daerah naungan. Gulma ini menjadi gulma penting pada perkebunan teh karena cukup merugikan (Ditbun, 2015). Hasil analisis korelasi menunjukkan tingkat dominansi Setaria plicata berkorelasi terhadap kadaar KTK, dan $\mathrm{pH}$ tanah. KTK merupakan jumlah total kation yang dapat dipertukarkan pada permukaan koloid yang bermuatan negatif (Soewandita H, 2008). Semakin tinggi kadar liat atau tekstur semakin halus maka KTK tanah akan semakin besar. Demikian pula pada kandungan bahan organic tanah, semakin tinggi bahan organik tanah maka KTK tanah akan semakin tinggi. Tingkat kemasaman tanah yang sesuai bagi gulma Setaria plicata akan mempengaruhi penyerapan unsurunsur hara dalam tanah. Tingkat kemasaman tanah juga berpengaruh terhadap perkembangan mikroorganisme di dalam tanah. Tingkat $\mathrm{pH}$ 5,5-7 bakteri dan jamur pengurai bahan organik dapat berkembang dengan baik.

\section{KESIMPULAN}

Aspek khusus yang dilakukan yaitu manajemen pengendalian gulma, secara khusus menentukan faktor- faktor penentu dominansi gulma. Berdasarkan hasil analisis vegetasi ditemukan 49 spesies gulma. Gulma yang mendominasi suatu lahan untuk setiap tahun tanam yang berbeda memiliki spesies gulma dominan yang berbeda juga. Pada tahun tanam 1990 gulma yang mendominasi adalah Andropogon aciculatus dengan NJD 21,04\%, pada tahun tanam 1994 gulma yang mendominasi adalah Digitaria ciliaris dengan NJD 30,57\%, pada tahun tanam 1998 gulma yang mendominasi adalah Eleusine indica dengan NJD 28,84\%, pada tahun tanam 2010 gulma yang mendominasi adalah Cynodon dactylon dengan NJD 23,39\%, pada tahun tanam 2013 gulma yang mendominasi adalah Digitaria ciliaris dengan NJD 17,97\%.

Faktor yang mempengaruhi pertumbuhan dan perkembangan setiap jenis gulma berbedabeda, dan agroekologi, serta tindakan budidaya yang berbeda akan menetukan jenis gulma dominan yang berbeda pula. Pada aspek klutur teknis yang dilakukan di kebun Dolok ilir, kegiatan pemupukan berkorelasi negatif pada tingkat dominansi Andropogon aciculatus dan tanaman penutup tanah berkorelasi negatif terhadap tingkat dominansi Digitaria ciliaris. Pada aspek edafik, dan iklim mikro tanaman kelapa sawit, tingkat dominansi gulma Rosetllularia rundana berkorelasi negatif terhadap suhu udara dan berkorelasi positif pada kandungan total unsur hara fosfor di dalam tanah. Tingkat dominansi gulma Setaria plicata berkorelasi positif terhadap kadar KTK tanah, dan $\mathrm{pH}$ tanah. Tingkat dominansi gulma Penissetum polystachion berkorelasi positif terhadap kadar kalium dalam tanah. Tingkat dominansi gulma Ottochloa nodosa yang mendominasi pada setiap daerah terbuka berkorelasi positif terhadap tingkat intensitas cahaya, dan berkorelasi negatif terhadap tingkat kelembapan.

\section{DAFTAR PUSTAKA}

[Cabi] Cookies on Invasive Species Conpendium. 2014. Cynodon dactlon (bermuda grass) . [Internet [diunduh 2016 Desember 13] tersedia pada http://www.cabi.org/isc/datasheet/17463

[Cabi] Cookies on Invasive Species Conpendium. 2014. Eleusine indica (goose grass). [Internet] [diunduh 2016 Desember 13] tersedia pada http://www.cabi.org/isc/datasheet/20675

[Cabi] Cookies on Invasive Species Conpendium. 2008. Pennisetum polystachion (mission grass) [Internet] [diunduh 2016 Desember 13] tersedia pada http://www.cabi.org/isc/datasheet/39770

Direktorat Jenderal Perkebunan. 2013. Perkembangan volume dan nilai ekspor komoditas primer perkebunan tahun 2008-2013. [Internet] [diunduh 2015 Maret 30] tersedia pada http://ditjenbun.pertanian.go.id/tinymcp uk/gambar/file/5.\%20Ekspor.pdf. 
D'Antonio, C.M., P.M. Vitousek. 1992. Biological invasions by exotic grasses, the grass/fire cycle, and global chance. Annual Review in Ecology and Systematics. 23:63-87.

Faisal R., Edy B.M.S., Nelly A. 2013. Inventarisasi gulma pada tegakan tanaman muda Eucalyptus spp. J. USU. 2(2):44-49Fauzi, Y., Y.E. Widyastuti, I. Satyawibawa, R. Hatono. 2002. Budidaya Pemanfaatan Hasil dan Limbah Analisis Usaha dan Pemasaran. Kelapa Sawit Seri Agribisnis, Cimanggis.

[Kementan] Kementrian Pertanian. 2013. Pengeloaan gulma pada perkebunan kelapa sawit. [Internet] [diunduh 2016 Desember 8] tersedia pada http://ditjenbun.pertanian.go.id/perlindu ngan/halkomentar-196-pengelolaangulma-pada-perkebunan-kelapa-7.html.

[Kementan] Kementrian Pertanian. 2014. Peran unsur kalium (K) bagi tanaman. [Internet] [diunduh 2016 Deember 16] tersedia pada http://www.bbpplembang.info/index.php/arsip/artikel/arti kel-pertanian/833-peran-unsur-harakalium-k-bagi-tanaman.

Kruidhof, H. M., Bastiaans, L., Kropff, M.J. Ecological weed management by cover cropping: effects on weed growth in autumn and weed establishment in spring. Weed Research. 48(6):492-502.

Mayadewi, N.N.A. 2007. Pengaruh jenis pupuk kandang dan jarak tanam terhadap pertumbuhan gulma dan hasil jagung manis. Agritrop. 26(4):153-159.

Nasution, H.K., Titiek, I., Husni, T.S. 2013. Pengaruh dosis pupuk anorganik dan pengendalian gulma pada pertumbuhan vegetatif tanaman tebu (Saccharum officinarum L.) varietas PS.881. J. Produksi Tanaman. 1(4):299-307.

Noorhadi, Sudadi. 2003. Kajian pemberian air dan mulsa terhadap iklim mikro pada tanaman cabai di tanah entisol. Jurnal Ilmu Tanah dan Lingkungan. 4(1): 4149.

Pahan, I. 2008. Panduan Lengkap Kelapa Sawit : Manajemen Agribisnis dari Hulu hingga Hilir. Penebar Swadaya, Jakarta.

Rosmarkam, Afandhie, W.Y. Nasih. 2002. Ilmu Kesuburan Tanah. Kanisius, Yogyakarta.

Salmiyati, H. Arien, I. Ida, S. Eko. 2014. Oil palm plantations managment effects on productivity fruit bunch (FFB). APCBEE Procedia 8: $282-286$.

Setyamidjaja, D. 2012. Budidaya Kelapa Sawit. Kanisius, Yogakarta.

Soewandita, H. 2008. Studi kesuburan tanah dan analisis kesesuaian lahan untuk komoditas tanaman perkebunan di Kabupaten Bengkalis. Jurnal sains dan teknologi Indonesia. 2(10): 128-133.

Tantra, A.W., E. Santosa. 2016. Manajemen gulma di Kebun Kelapa Sawit Bangun Bandar: analisis vegetasi dan seedbank gulma. Bul. Agrohorti 4(2): 138-143 (2016). 